\title{
IDENTITAS BANGUNAN KOTA LAMA SEBAGAI BAGIAN KOMUNIKASI PERSUASIF DALAM PARIWISATA
}

\author{
Mukaromah $^{1}$, Astini Kumalasari ${ }^{2}$ \\ 1,2 Prodi Ilmu Komunikasi, Fakultas Ilmu Komputer,Universitas Dian Nuswantoro \\ mukaromah@dsn.dinus.ac.id ${ }^{1}$, astini.kumalasari@dsn.dinus.ac.id ${ }^{2}$
}

\begin{abstract}
Abstrak
Kota Semarang yang membidik sektor pariwisata, berupaya menampilkan identitas ikon kota yang lebih variatif tidak hanya Tugumuda dan Lawang Sewu. Kawasan Kota lama Semarang adalah salah satu prioritas. Instagram adalah media pilihan untuk kegiatan sosialisasi ikon kota dengan target bidik anak muda. Akun instagram @disbudparkotasemarang adalah akun resmi dinas kebudayaan Kota Semarang yang mengelola urusan wisata di kota ini. Penelitian ini menunjukkan bahwa intensitas jumlah postingan, gambar yang diunggah, pesan captions yang ditulis mampu mempengaruhi benak khalayak demikian juga pada media Instagram. Teori Agenda Setting mengemukakan bahwa isi media dapat dibingkai oleh pengelola untuk tujuan yang diinginkan dengan pendekatan persuasif. Tujuannya ingin mengetahui isi unggahan, intensitas identitas ikon bangunan kawasan Kota lama yang kerap ditampilkan, teknik penulisan captions pada akun instagram @disbudparkotasemarang yang erat hubungannya dengan komunikasi persuasif untuk menarik kunjungan. Pendekatan penelitian kuantitatif dengan metode analisis isi atas unggahan yang diamati. Hasilnya adalah Gereja Blenduk merupakan ikon bangunan yang sering diunggah yaitu 60 kali unggahan. Tahun 2019 adalah tahun paling banyak menampilkan postingan terkait kota lama sebanyak 54 postingan. Unggahan foto pada 30 Desember 2019 paling banyak banyak disuka orang, terdapat 947 Likes. Teknik penulisan persuasif dengan pendekatan teknik tataan adalah teknik penulisan captions yang sering digunakan.
\end{abstract}

Kata Kunci : identitas kota, komunikasi persuasif, Kota Lama Semarang

\begin{abstract}
The city of Semarang, which is aiming at the tourism sector, seeks to display a more varied identity of city icons, not only Tugumuda and Lawang Sewu. The old Semarang city area is one of the priorities. Instagram is the media of choice for city icon socialization activities that target young people. The @disbudparkotasemarang account is an official account owned by the Semarang city culture office, which manages tourism affairs in the city. The urgency of this study is that the intensity of the number of posts, images uploaded, captions messages that written can affect the minds of audiences as well as on Instagram media. The Agenda Setting Theory presented that media content framed by managers for desired purposes in a persuasive manner. The goal is to find out the contents of the upload, the intensity of the identity of the old city building icon that often displayed, captionswriting technique on the @disbudparkotas account now that is closely related to persuasive communication to attract visits. Quantitative research approaches with content analysis methods for observed uploads. The result, Blenduk church is a building icon that is often uploaded, which is 60 uploads. 2019 is the year were the most 54 posts posted in the city. The photo uploads on Dec 30, 2019, have the most likes, 947 Likes. Persuasive Writing Techniques with the approach to setting techniques are captions writing techniques that often used.
\end{abstract}

Keywords: city identity, old town, persuasive communication 


\section{PENDAHULUAN}

Identitas kota merupakan bagian penting dari branding suatu kota. Salah satu wujud pembentukan identitas Kota Semarang adalah dengan menampilkan potensi wisata destinasi bangunan cagar budaya. Identitas merupakan hal yang kuat dalam kesamaan dan kesatuan, sehingga dapat dibedakan dari yang lainnya (Inn, 2004:234). Identitas kota merupakan sesuatu yang unik yang membedakan dengan kota lainnya. Identitas sebuah kota memegang peranan penting bagi masyarakat lokal maupun pengunjung dalam konteks berbeda-beda. Evers dan Korff dalam Suprayoga (2008:2-3) menyampaikan bahwa bangunan-bangunan yang khas merupakan simbol dan tanda penunjuk identitas sekaligus landasan dalam mewujudkan citra per kota. Konsep place identity yang mengacu pada hubungan antara place dengan identity yang menekankan pada makna dan signifikansi "tempat" bagi para penghuni dan pengguna tempat tersebut (Ernawati, 2014;22). Kawasan Kota lama Semarang adalah bagian kawasan yang syarat akan nilai sejarah dan bangunan cagar budayanya.

Kota Semarang, sebagaimana disampaikan dalam website pemerintah kota mulai berbenah diri dengan membangun beberapa potensi untuk membidik sektor jasa pariwisata (Pujakesuma: 2019; semarangkota.go.id, 2018) dari yang sebelumnya sebagai kota jasa perdagangan atau kota transit. Salah satu upaya dalam menyampaikan potensi wisatanya dengan melakukan berbagai kegiatan komunikasi pariwisata. Wujudnya salah satunya yaitu dengan mengkomunikasikan ciri khas lain akan Kota Semarang. Keontentikan suatu wilayah adalah hal yang penting dalam komunikasi di bidang pariwisata. Ratiu dalam jurnal city, culture and society mengatakan bahwa pembangunan kota yang kreatif dengan menonjolkan identitas sosial dan komunal yang dimiliki masyarakatnya adalah penting (Ratiu, 2013:125). Dalam komunikasi strategis, juga menyebutkan bahwa orisinalitas/ otentifikasi kota itu penting agar memiliki nilai deferensiasi atau pembeda dengan kota lain sehingga cara pengkomunikasian kota satu dengan kota lainnya juga akan berbeda.

Masalahnya adalah identitas ikon Kota Semarang yang sudah melekat di benak masyarakat terbatas dan hanya itu-itu saja seperti warak ngendog (Adiwibawa \& Prabowo, 2016), Tugumuda dan Gedung Lawang Sewu (Yanuarsari \& Haryadi, 2019). Pemerintah Kota Semarang berusaha mengembangkan kawasan kota Lama dengan bangunan cagar budayanya sebagai ikon kota yang juga identik dengan Kota Semarang (radarsemarang.jawapos.com, 2019). Kawasan Kota Lama Semarang adalah bagian dari destinasi unggulan yang akan dioptimalkan oleh pemerintah kota karena nilai keotentikan/ keaslian pada sejarah dan kawasan peninggalan budaya.

Sosialisasi beberapa bangunan ikonik terkait kawasan kota lama terus digencarkan agar muncullah identitas kota yang baru bagi Kota Semarang. Salah satu media yang digunakan adalah melalui media sosial instagram. Berdasarkan data dari Badan Pusat Statistik sebagaimana dikutip oleh katadata.co.id, menyebutkan bahwa berdasarkan golongan usia, umur 15-34 tahun merupakan kelompok umur yang menduduki porsi sebesar 30,82\% sendiri dibanding kelompok usia lain. Kelompok ini adalah user friendly pengguna media sosial. Berdasarkan data yang dikutip dari napoleonchat dalam 
tekno.kompas.com menyebutkan hingga November 2019, pengguna aktif instagram di Indonesia mencapai 61.616 .000 juta jiwa. Angka pengguna instagram ini didominasi untuk pengguna usia 18-24 tahun dan kelompok 25-34 tahun .

Akun@disbudpakotasemarang adalah sebagai akun resmi yang dimiliki oleh Dinas Pariwisata Kota Semarang. Dinas ini menjadi punggawa pelaksaan kegiatan pariwisata di Kota Semarang dari perwakilan pemerintah kota ini, sehingga akun ini dianggap sebagai salah satu representasi pemerintah dalam menampilkan kawasan Kota Lama. Urgensi penelitian ini yaitu untuk mengetahui bahwa intensitas jumlah postingan, intensitas gambar yang diunggah, pesan captions yang ditulis mampu mempengaruhi benak khalayak. Dalam konteks komunikasi, teori Agenda Setting mengemukakan bahwa isi media dapat di framing oleh pengelola untuk tujuan yang diinginkan (MCCombs \& Shaw, 2019). Tujuan dalam penelitian ini adalah ingin mengetahui bagaimana isi unggahan, penggambaran identitas ikon bangunan kawasan Kota lama yang kerap ditampilkan, teknik penulisan captions kepada khalayak pada akun instagram@disbudparkotasemarang yang erat hubungannya dengan komunikasi persuasif.

Persuasi ialah usaha mempengaruhi pikiran dan perbuatan individu, atau hubungan aktivitas antara komunikator dan komunikan yang mana komunikator berusaha mempengaruhi tingkah laku komunikan atau audiens melalui pendengaran dan penglihatan. Sementara komunikasi persuasif ialah proses komunikasi yang bertujuan mempengaruhi pemikiran dan pendapat orang lain agar menyesuaikan pendapat dan keinginan komunikator, tujuannya tidak hanya untuk memberitahu, tapi juga mengubah sikap, pendapat, atau perilaku (Putri et al., 2015).

Dalam menyampaikan komunikasi persuasif dikenal dengan beberapa teknik pendekatan. Effendy dalam (Erviani, 2017: 239) menjabarkan teknik-teknik dalam komunikasi persuasif yaitu: (1) Teknik Asosiasi adalah penyajian pesan komunikasi dengan cara menumpahkannya pada suatu obyek atau peristiwa yang sedang menarik perhatian khalayak. (2) Teknik Integrasi ialah kemampuan komunikator untuk menyatukan diri secara komunikatif dengan komunikan. Ini berarti bahwa melalui katakata verbal maupun non verbal komunikator menggambarkan bahwa ia "senasib" dan dengan karena itu menjadi satu dengan komunikan. (3) Teknik Ganjaran adalah kegiatan untuk mempengaruhi orang lain dengan cara mengiming-iming hal yang menguntungkan atau menjanjikan harapan. (4) Teknik Tataan adalah upaya menyusun pesan komunikasi sedemikian rupa, sehingga enak didengar atau dibaca dan menimbulkan motivasi untuk melakukan sebagaimana disarankan oleh pesan tersebut. (5)Teknik Red-herring adalah seni seorang komunikator untuk meraih kemenangan dalam perdebatan dengan mengelakkan argumentasi yang lemah untuk kemudian mengalihkannya sedikit demi sedikit ke aspek yang dikuasainya guna dijadikan senjata ampuh dalam menyerang lawan.

Menurut Kevin Lynch, Identitas Kota adalah citra mental yang terbentuk dari ritme biologis tempat dan ruang tertentu yang mencerminkan waktu (sense of time), yang 
ditumbuhkan dari dalam secara mengakar oleh sosial-ekonomi-budaya masyarakat itu sendiri. Identitas adalah suatu kondisi saat seseorang mampu mengenali atau memanggil kembali (ingatan) suatu tempat yang memiliki perbedaan dengan tempat yang lain karena memiliki karakter dan keunikan (Lynch, 1960). Beberapa tempat dianggap lebih penting dibanding tempat lain karena atribut atribut fisik yang dimilikinya dan karena jenis-jenis aktivitas yang terjadi pada tempat tersebut (Ernawati, 2014:2).

\section{METODE PENELITIAN}

Metode yang digunakan dalam penelitian ini yaitu dengan menggunakan analisa isi kuantitatif. Dengan populasi yang diambil adalah seluruh unggahan atau postingan pada obyek pengamatan penelitian yaitu akun instagram @disbudparkotasemarang. Akun diamati dari tahun 2016 saat awal pertama adanya postingan hingga akhir pengamatan pada Januari 2020. Kemudian data diambil secara keseluruhan atas postingan yang berhubungan dengan Kawasan kota lama Semarang. Data dikumpulkan dengan menampilkan seluruh postingan berupa video, gambar, foto dan teks tentang kawasan kota lama Semarang yang meliputi tanggal unggahan, jenis unggahan, frekuensi ungaghan, gambar unggahan. Data ini kemudian dilakukan pengelompokan berdasarkan kebutuhan dan tujuan penelitian.

Klasifikasi berdasarkan ragam identitas bangunan gedung cagar Budaya Kota lama yang sering diunggah untuk menunjukkan ikon bangunan apa yang sering ditampilkan, berapa jumlah postingan per tahun, postingan apa yang paling mendapatkan banyak respon baik likes atau views. Kemudian data ini dianalisis dengan menggunakan teori Agenda Setting dengan pendekatan persuasif untuk memberi penjelasan, membandingkan data dengan captions yang diunggah dan keterangan dari informan pendukung, juga sumber data sekunder untuk penambah referensi, sehingga dapat ditarik kesimpulan atas telaah isi kuantitatif atas tampilan akun instagram @disbudparkotasemarang.

\section{HASIL DAN PEMBAHASAN}

Akun instagram @disbudparkotasemarang ini merupakan akun resmi yang dikelola oleh Dinas Kebudayaan dan Pariwisata Kota Semarang. Memiliki total 975 kiriman (postingan) yang diunggah sejak tahun 2016 dengan pengikut sejumlah 13.000 akun atau follower per februari 2020.

Berikut ini data terkait unggahan atau postingan terkait kota lama Semarang yang nampak pada bagian Feed Instagram @disbudparkotasemarang yang diamati sejak unggahan pertama tahun 2016 hingga Januari 2020 dan terdapat 46 Postingan yang berhubungan dengan kawasan kota lama, bisa dalam bentuk unggahan foto, video, maupun teks, captions status. Dari postingan tersebut dapat di kelompokkan data bahwa

\subsection{Identitas Bangunan Gedung di Kawasan Kota Lama yang Sering Diunggah di Akun Instagram @disbudparkotasemarang}

Berdasarkan jumlah unggahan, gedung yang paling sering diunggah di postingan pada feed instagram akun instagram @disbudpaskotasemarang terkait kawasan kota lama 
adalah Gereja Blenduk, sebanyak tidak kurang dari 23 kali unggahan. Ungahan ini menampilkan gereja blenduk dari sisi outdoor bangunan maupun indoor. Gereja Blenduk menjadi identitas tersendiri bagi kawasan kota lama Semarang dengan bentuk bangunannya yang khas dengan kubah setengah lingkarannya.

Disusul kemudian dengan gedung Spiegel sebanyak 12 kali unggahan yang ke semuanya menampilkan sisi outdoor. Gedung Spiegel yang terletak di Jalan Letjen Soeprapto dekat dengan taman Srigunting pada awal abad ke-19 sampai dengan akhir pemerintahan kolonial Belanda merupakan toko yang menjual berbagai barang seperti alat-alat tulis, mesin ketik, alat-alat olah raga, tekstil, furniture, dan alat-alat rumah tangga. Sekarang gedung Spiegel digunakan untuk coffee shop, dan ruang pertemuan, co-working space.

Sementara gedung yang menduduki kelompok ketiga gedung yang sering muncul dalam unggahan instagram @disbudparkotasemarang adalah gedung Marba sebanyak 9 kali unggahan. Kesemuanya ditampilkan versi tampak outdoor dan fasad depan bangunan yang didominasi warna orange dengan list gedung warna putih yang tampak berdiri kokoh di jalan Letjen Soeprapto Semarang. Gedung Marba menurut sejarahnya adalah kepanjangan dari Marta Badjunet (disingkat Marba) singkatan dari pemilik gedung ini, yaitu seorang saudagar kaya dari Yaman. Dulunya gedung ini di fungsikan sebagai kantor usaha pelayaran, Ekspedisi Muatan Kapal Laut / EMKL.

Bentuk penyajian unggahan penampakan gedung tidak semua sendiri sendiri, tetapi gabungan/kompilasi beberapa video yang menampilkan beberapa gedung dalam sekali postingan memungkinkan terjadi. Dan dalam pengajian data ini dihitung setiap tampilan gedung meski disajikan secara kompilasi baik bentuk video maupun kolase foto. Beberapa hasil foto Unggahan tersebut diantaranya:

Tabel 1. Beberapa contoh unggahan 3 Gedung yang paling sering muncul di akun@ disbudparKota Semarang

[Sumber: @disbudparkotasemarang]

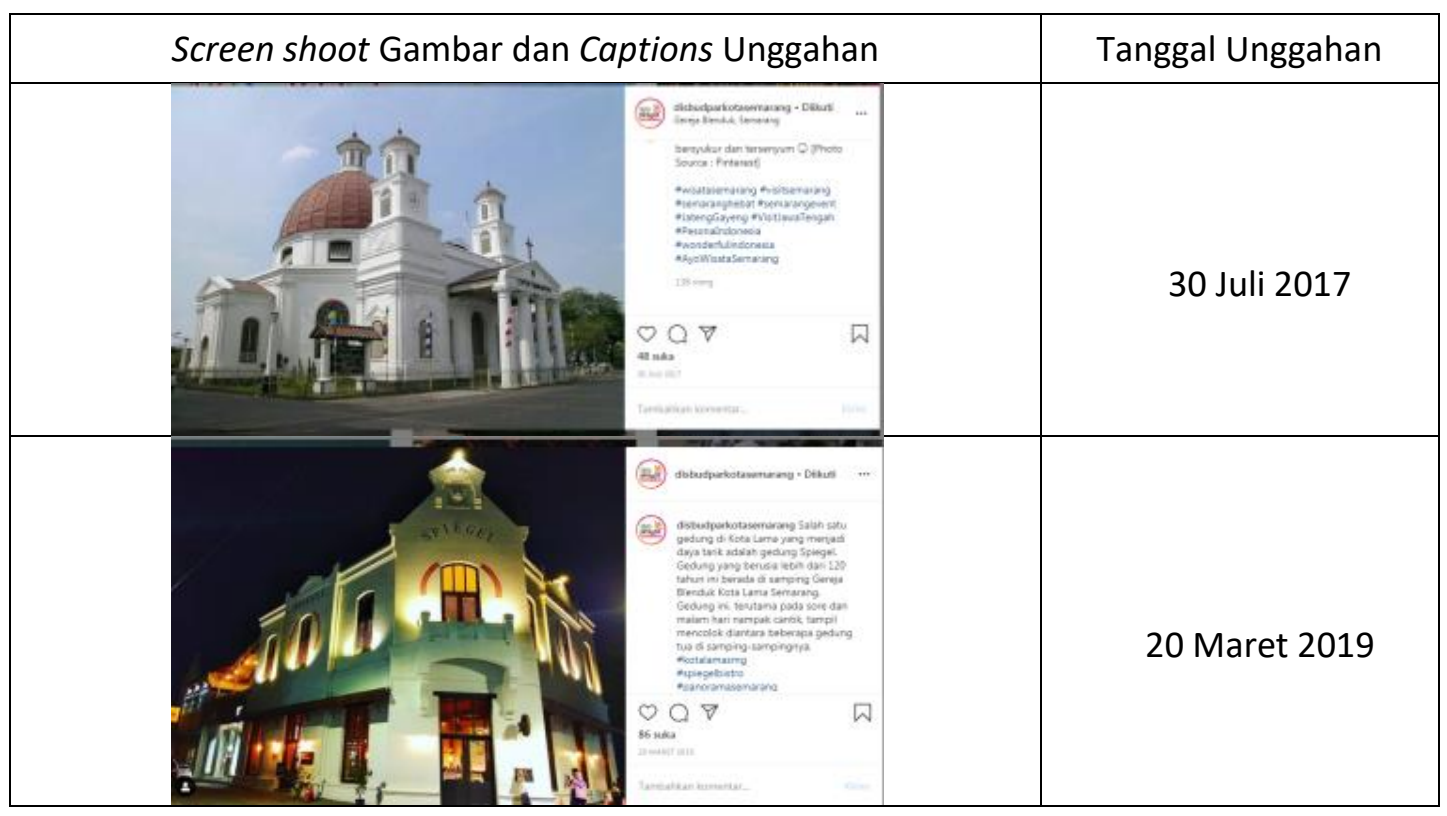




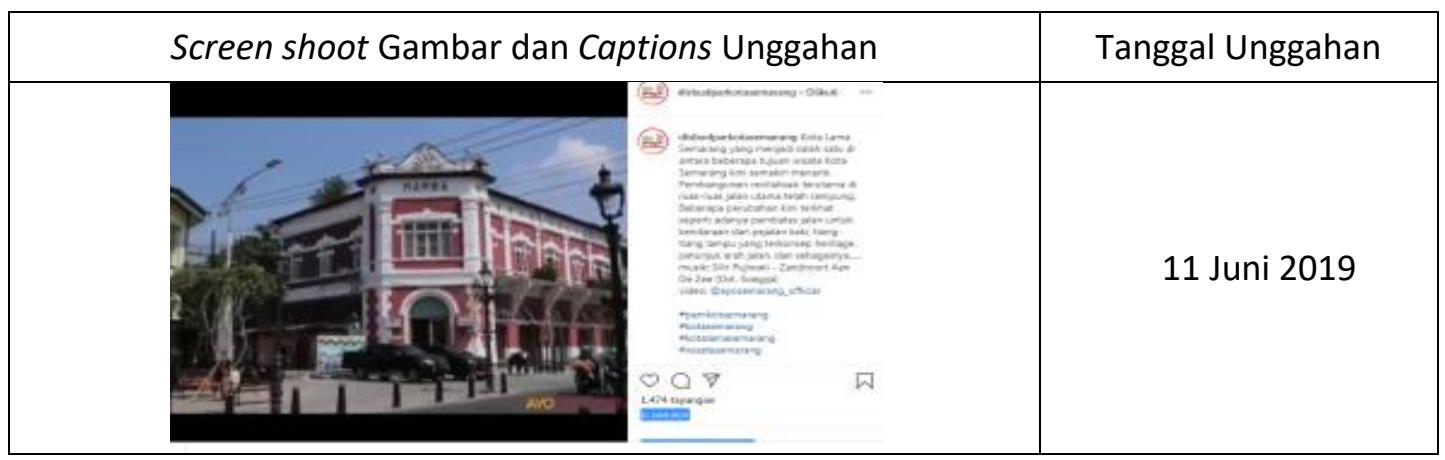

Berikut ini hasil penyajian data gedung di kawasan Kota lama Semarang yang sering diunggah melalui akun instagram @disbudparkotasemarang.

Tabel 2. Intensitas unggahan Gedung Kota Lama Semarang di akun instagram @disbudparkotasemarang berdasarkan tanggal unggahan

[Sumber: olah data peneliti Periode tahun 2016-Januari 2020]

\begin{tabular}{|c|c|c|c|}
\hline No & Nama Gedung & Tanggal Unggahan & $\begin{array}{c}\text { Jumlah } \\
\text { Unggahan }\end{array}$ \\
\hline 1 & Gereja Blenduk & $\begin{array}{l}2 \text { Februari 2017; } 12 \text {, } 30 \text { Juli 2017; } \\
\text { 16,30 Mei 2019; } 11 \text { Juni 2019; 3,21,22,29,30 } \\
\text { September 2019; 2,7,10,11,13,27 Oktober } \\
\text { 2019; 21, } 27 \text { Nov 2019; 11,19,25,28 Des } \\
2019 .\end{array}$ & 23 \\
\hline 2 & Gedung Spiegel & $\begin{array}{l}20 \text { Maret 2019; } 27 \text { Mei 2019; } 6 \text { Juni 2019; } \\
21 \text { Agustus 2019; 2,7,11,13, } 27 \text { okt 2019; } \\
\text { 11, 19, } 20 \text { Desember } 2019\end{array}$ & 12 \\
\hline 3 & Gedung Marba & $\begin{array}{l}16 \text { Mei 2019; } 11 \text { Juni 2019; } \\
\text { 2, 13,11, } 27 \text { Okt 2019; } 21 \text { Nov 2019; } \\
\text { 19,20 Desember 2019, } 1 \text { Januari } 2020\end{array}$ & 9 \\
\hline 4 & $\begin{array}{l}\text { Gedung Nederlandsche Handel } \\
\text { Maatschappij atau Sekarang } \\
\text { untuk Gedung Bank Mandiri }\end{array}$ & $\begin{array}{l}17 \text { Oktober 2018; } 16 \text { Mei 2019; } 24 \text { Juni } \\
\text { 2019; } 29 \text { September 2019; } \\
\text { 11,27 Oktober 2019, } 11 \text { Des } 2019\end{array}$ & 7 \\
\hline 5 & Gedung Oudetrap & $\begin{array}{l}23 \text { Agustus 2019; } 25 \text { Sept 2019; } \\
11 \text { Oktober 2019; 10,20 Desember 2019; } \\
\text { 1,10 Januari } 2020\end{array}$ & 7 \\
\hline 6 & $\begin{array}{l}\text { Lain-lain ( gedung Phapros, } \\
\text { gedung arsip, gedung Soesman } \\
\text { Kantoor, Gedung restoran IBC, } \\
\text { kantor jiwasraya, old city } \\
\text { museum,dmz museum, } \\
\text { Gedung Semarang Kreatif } \\
\text { Galeri dan lain-lain) }\end{array}$ & $\begin{array}{l}24 \text { Januari 2018; } 16 \text { Mei 2019; } 11 \text { Juni 2019; } \\
29 \text { Sept 2019; 11,17 Oktober 2018; } 22 \\
\text { Agustus 2019; 19, } 20 \text { Desember 2019,1 } \\
\text { Januari } 2020 .\end{array}$ & $1-5$ \\
\hline
\end{tabular}

\subsection{Jumlah Unggahan per Tahun pada Akun @disbudparkotasemarang}

Jumlah Unggahan atau postingan berdasarkan tahun, diketahui bahwa tahun 2019 menjadi tahun dengan postingan terbanyak terkait kawasan kota lama semarang yaitu sejumlah 54 postingan dari total 60 postingan di feed instagram @disbudparkotasemarang periode pengamatan tahun 2016 hingga Januari 2020. 
Tabel 3. Jumlah postingan berdasarkan tahun

[Sumber: olah data peneliti Periode tahun 2016-Januari 2020]

\begin{tabular}{|c|l|l|}
\hline No & \multicolumn{1}{|c|}{ Tahun } & \multicolumn{1}{|c|}{ Jumlah postingan } \\
\hline 1 & 2016 & - \\
\hline 2 & 2017 & 2 postingan \\
\hline 3 & 2018 & 2 postingan \\
\hline 4 & 2019 & 54 postingan \\
\hline 5 & 2020 ( bln Januari) & 2 postingan \\
\hline
\end{tabular}

Dari data diatas tahun 2016 saat awal akun ini dibuat oleh Dinas Kebudayaan Kota Semarang pertama kali, postingan lebih banyak menampilkan sudut lain tentang Kota Semarang seperti Tugu Muda, Kawasan Simpang Lima, Kegiatan-kegiatan yang dilakukan terkait Dinas Kebudayaan Kota Semarang dan Pemkot Semarang. Selain itu pada tahun 2016 berdasarkan hasil observasi kawasan kota lama Semarang relatif belum terurus terlihat kumuh, banjir dan kurang begitu terawat atau terevitalisasi seperti sekarang, kondisi bangunan, jalan dan kawasan sekitar dan ketersediaan transportasi masih memprihatinkan sehingga belum bisa dijadikan sebagai destinasi unggulan pariwisata Kota Semarang.

Tahun 2019 banyak unggahan postingan mengenai kota lama, karena pada tahun ini kawasan kota lama Semrang sudah di percantik dan di revitalisasi oleh pemerintah kota lama Semarang dengan melakukan perbaikan gedung, tanpa mengurangi nilai cagar budayanya, membongkar pedestrian, memperbaiki saluran agar tidak banjir, memperbaiki kondisi jalan dan akses transportasi, menata lingkungan sehingga layak untuk dijadikan salah satu destinasi dan identitas tujuan wisata.

\subsection{Unggahan dengan Jumlah Views dan Likes Terbanyak}

Berdasarkan hasil pengamatan atas analisa isi akun instagram @disbudparkotasemarang, unggahan berbentuk video yang memiliki jumlah views terbanyak terkait kota lama Semarang adalah unggahan pada tanggal 28 Desember 2019, tercatat sebanyak 1764 tayangan. Postingan tanggal 22 Juli 2019 menduduki peringat kedua perolehan views terbanyak yaitu sejumlah 1648 views. Tercatat ada 17 kali unggahan berbentuk video berdasarkan periode pengamatan.

Tabel 4. Unggahan dengan jumlah views

[Sumber: olah data peneliti Periode tahun 2016-Januari 2020]

\begin{tabular}{|c|l|c|}
\hline No & Tanggal Unggahan & Jumlah Views \\
\hline 1 & 28 Des 2019 & 1764 \\
\hline 2 & 22 Juli 2019 & 1648 \\
\hline 3 & 21-Nov-19 1584 \\
\hline 4 & 11 Juni 2019 & 1474 \\
\hline 5 & 11 Okt 2019 & 1029 \\
\hline 6 & 13 Okt 2019 & 871 \\
\hline 7 & 6 Juni 2019 & 747 \\
\hline
\end{tabular}




\begin{tabular}{|c|l|c|}
\hline No & Tanggal Unggahan & Jumlah Views \\
\hline 8 & 12 Mei 2019 & 641 \\
\hline 9 & $14-S e p-19$ & 614 \\
\hline 10 & $29-$ Sep-19 & 594 \\
\hline 11 & 7 Okt 2019 & 552 \\
\hline 12 & 19 Des 2019 & 542 \\
\hline 13 & 27 Okt 2019 & 444 \\
\hline 14 & 16 Mei 2019 & 372 \\
\hline 15 & 27 Okt 2019 & 338 \\
\hline 16 & 25 Des 2019 259 \\
\hline 17 & 12 Juli 2017 & 128 \\
\hline
\end{tabular}

Unggahan video yang paling banyak mendapatkan views hingga 1764 yang diunggah pada tanggal 28 Desember 2019 yaitu video yang berisi tentang destinasi beberapa Wisata Kota Semarang Paling Hit. Salah satunya adalah kawasan kota lama, yang mana dalam video tersebut berupa destinasi untuk tujuan liburan akhir tahun bila ke Kota Semarang. Ada spot tampilan kota lama yaitu bangunan Gereja Blenduk, Gedung Jiwasraya dan Gedung Spiegel.

Tabel 5. Berdasarkan Jumlah Likes Pada Foto /Gambar Terbanyak

[Sumber: olah data peneliti Periode tahun 2016-Januari 2020]

\begin{tabular}{|c|l|c|}
\hline No & Tanggal Unggahan & Jumlah Like Gambar/foto \\
\hline 1 & 30 Des 2019 & 947 \\
\hline 2 & 1 Januari 2020 & 381 \\
\hline 3 & 11 Okt 2019 & 432 \\
\hline 4 & 20 Des 2019 & 365 \\
\hline 5 & 23 Agustus 2019 & 327 \\
\hline 6 & 5 Okt 2019 & 301 \\
\hline 7 & 11 -Sep-19 & 256 \\
\hline 8 & 27 Mei 2019 & 232 \\
\hline 9 & 24 Juni 2019 & 230 \\
\hline 10 & 22-Sep-19 & 226 \\
\hline 11 & 10 Okt 2019 & 212 \\
\hline
\end{tabular}

Sedangkan berdasarkan unggahan yang berbentuk foto, gambar maupun poster/banner (2 dimensi) terdapat 11 Unggahan selama kurun waktu pengamatan. Berdasarkan tabel unggahan penyuka foto terbesar sejumlah 947 likes terjadi pada tanggal 30 Desember 2019. Disusul kemudian dengan angka likes yang cukup jauh dari peringkat pertama yaitu hanya 381 Likes yang diunggah pada tanggal 1 Januari 2020.

Data menunjukkan bahwa foto yang diunggah pada tanggal 30 Desember 2019 adalah foto yang menampilkan kunjungan kerja presiden Joko Widodo saat mengunjungi kota lama dengan menaiki sepeda bersama dengan beberapa menteri Kabinet antara lain Menteri Keuangan Sri Mulyani, Menteri Luar Negeri Retno Marsudi, Menteri PUPR Basuki Hadimuljono dan menteri Pariwisata Wisnutama. Pada kesempatan itu juga turut 
didampingi juga oleh gubernur Jawa Tengah Ganjar Pranowo dan wali Kota Semarang Hendrarprihadi. Berikut Tampilan Foto yang disukai sebanyak 947 likes tersebut:

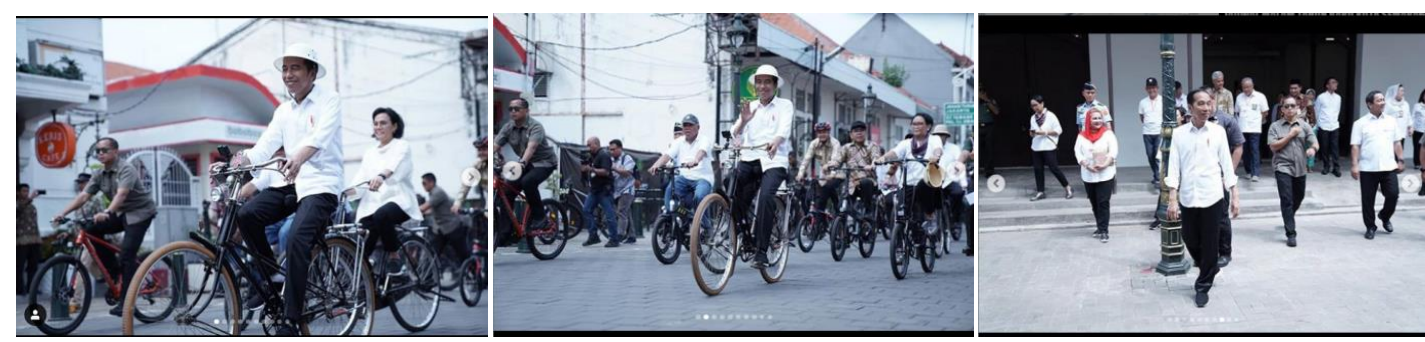

Gambar 1. Kunjungan Presiden Joko Widodo ke Semarang [Sumber: akun@disbudparkotasemarang]

\subsection{Jumlah Postingan Video dan Gambar/Foto per Tahun}

Data yang disajikan dibawah ini adalah memisahkan jumlah postingan dalam bentuk video dan gambar/foto. Didapatkan data bahwa terdapat masing-masing 1 unggahan baik video maupun foto di tahun 2017, sementara masing masing ada 2 unggahan foto untuk tahun 2018 dan 2020 hingga bulan Januari. Postingan video tertinggi ada di tahun 2019 dan postingan gambar/foto tertinggi ada di tahun 20019 juga sebesar 38 unggahan.

Tabel 6. Jumlah postingan Video dan Gambar/foto per Tahun yang berhubungan dengan kawasan Kota Lama Semarang

[Sumber: olah data peneliti Periode tahun 2016-Januari 2020]

\begin{tabular}{|l|c|c|}
\hline \multicolumn{1}{|c|}{ Tahun } & $\begin{array}{c}\text { Jumlah Video } \\
\text { yang diunggah }\end{array}$ & $\begin{array}{c}\text { Jumlah Gambar/foto } \\
\text { yang diunggah }\end{array}$ \\
\hline 2016 & - & - \\
\hline 2017 & 1 & 1 \\
\hline 2018 & - & 2 \\
\hline 2019 & 16 & 38 \\
\hline 2020 ( bln Jan 2020) & - & 2 \\
\hline Jumlah & 17 & 43 \\
\hline
\end{tabular}

\subsection{Teknik Penulisan Captions yang Digunakan}

Dari total 60 postingan pada feed akun instagram @disbudparkotasemarang, berdasarkan cara menulis captions menggunakan 4 teknik menulis secara persuasif yaitu teknik asosiasi, teknik integrasi,teknik ganjaran dan teknik tataan. Berdasarkan pengamatan atas data tulisan yang terkumpul, teknik secara Red Herring belum muncul dari ke-60 postingan unggahan. Hal ini bisa dimengerti karena teknik Red herring adalah seni komunikator atau dalam hal ini pembuat konten, berusaha bagimana untuk meraih kemenangan dalam perdebatan degan berusaha melawan argumen yang lemah dan kemudian mengalihkan sedikit demi sedikit aspek yang dikuasainya untuk menyerang lawan.

Berikut ini hasil dari pengelolaan hasil analisa isi teks caption terkait sebaran teknik persuasi yang digunakan dalam akun instagram @disbudpaskotasemarang. 
Tabel 7. Sebaran teknik persuasi pada akun @disbudparkotasemarang [Sumber: olah data peneliti Periode tahun 2016-Januari 2020]

\begin{tabular}{|c|l|l|l|}
\hline No & \multicolumn{1}{|c|}{ Jenis Teknik Persuasi } & \multicolumn{1}{|c|}{ Jumlah } & \multicolumn{1}{|c|}{ Prosentase } \\
\hline 1 & Teknik Tataan & 20 & $33.33 \%$ \\
\hline 2 & Teknik Integrasi & 11 & $18,33 \%$ \\
\hline 3 & Teknik Ganjaran & 13 & $21,67 \%$ \\
\hline 4 & Teknik Asosiasi & 5 & 8,34 \\
\hline 5 & Tidak menunjukkan teknik persuasi & 11 & $18,33 \%$ \\
\hline & Jumlah & 60 & $100 \%$ \\
\hline
\end{tabular}

Berdasarkan tabel 7 tersaji data bahwa teknik pengajian persuasi dengan pendekatan teknik tataan menduduki porsi yang paling besar yaitu sebesar $33,33 \%$ atau sejumlah 20 postingan dalam bentuk captions dan teknik asosiasi paling jarang digunakan selama masa obyek pengamatan yaitu sebesar $8,34 \%$ atau sebanyak $5 \%$.

\subsection{Analisa Foto dan Video dengan Penulisan Captions yang Digunakan}

Pada bagian ini pengamatan dan analisa hanya dilakukan terhadap unggahan foto dan video yang memiliki respon terbanyak yaitu dari like dan views.

Tabel 8. Tabel video dan foto dengan captions pada unggahan dengan respon terbanyak pada akun instagram @disbudparkotasemarang

[Sumber: olah data peneliti Periode tahun 2016-Januari 2020]

\begin{tabular}{|l|l|l|l|l|}
\hline $\begin{array}{l}\text { Tanggal } \\
\text { Unggah }\end{array}$ & Respon & \multicolumn{1}{|c|}{ Gambar/Video unggahan } & \multicolumn{1}{c|}{ Captions } \\
\hline $\begin{array}{l}28 \\
\text { Des } 2019\end{array}$ & $\begin{array}{l}1764 \\
\text { tayangan }\end{array}$ & $\begin{array}{l}\text { Destinasi Wisata Kota Semarang } \\
\text { Paling Hitzzz } \\
\text { "Hidup didunia ini indah } \\
\text { kalau hidupmu tidak indah, itu } \\
\text { tandanya kamu kurang bersyukur } \\
\text { dan Kurang Piknik" } \\
\text { Nomentar }\end{array}$ & $\begin{array}{l}\text { Naah buat yang akan atau sudah } \\
\text { berada di Kota Semarang, banyak } \\
\text { pilihan destinasi wisatanya nih } \\
\text { untuk mengisi hari liburan kalian.. } \\
\text { Ayok Selamatkan Anak Bangsa dari } \\
\text { Bahaya Kurang Piknik" (9.) }\end{array}$ \\
\hline
\end{tabular}




\begin{tabular}{|c|c|c|c|}
\hline $\begin{array}{l}\text { Tanggal } \\
\text { Unggah }\end{array}$ & Respon & Gambar/Video unggahan & Captions \\
\hline $\begin{array}{l}30 \\
\text { Des } 2019\end{array}$ & $\begin{array}{l}947 \text { suka } \\
\text { Dengan } \\
12 \\
\text { komentar }\end{array}$ & & $\begin{array}{l}\text { Selamat datang di Kota Semarang } \\
\text { Bapak Presiden Republik } \\
\text { Indonesia @jokowi beserta Ibu } \\
\text { menteri Keuangan @smindrawati, } \\
\text { Ibu menteri Luar } \\
\text { Negeri @retno_marsudi , Bapak } \\
\text { menteri } \\
\text { PUPR @basuki_hadimuljono dan } \\
\text { Mas menteri Pariwisata dan } \\
\text { Ekonomi Kreatif @wishnutama } \\
\text { Dalam rangka kunjungan kerja } \\
\text { pemantauan Revitalisasi tahap } \\
\text { pertama Pasar Johar, alun -alun } \\
\text { Kota Semarang dan Kawasan Kota } \\
\text { Lama Semarang. } \\
\text { Terima kasih atas perhatiannya } \\
\text { untuk Kota Semarang. }\end{array}$ \\
\hline
\end{tabular}

Analisa terkait foto yang memiliki jumlah likes terbanyak sebagaimana tabel 8 yaitu foto terkait kunjungan presiden Jokowi ke Kota lama Semarang, yang terunggah pada tanggal 30 Desember 2019 dengan 947 likes, berisikan captions yang cenderung formal dengan pesan tulisan yang berisikan terkait ucapan selamat datang dan tujuan kunjungan kerja yang dilakukan oleh presiden dengan stafnya. Tidak nampak unsur teknik persuasifnya bahkan cenderung pesan yang sifatnya formal. Unggahan inipun mendapatkan komentar khalayak hanya berjumlah 12 komentar jauh dari jumlah 947 likes yang ada. Hal ini dapat disebabkan beberapa hal antara lain, kekuatan foto dan tokoh yang tersaji dalam unggahan yang merupakan tokoh yang popular sudah cukup mewakili untuk khalayak menyukai. Dalam komunikasi hal ini terkait new value berita yaitu unsur prominence atau ketokohan seseorang (name make news). Faktor lain yang dapat dianalisa mengapa jumlah like lebih banyak daripada jumlah komentar, kemungkinan besar terkait kemudahan menekan simbol/tombol like yang tersimbolkan dengan bentuk love lebih mudah dari pada harus menulis kalimat dalam komentar.

Terkait unggahan video yang banyak mendapatkan respon khalayak (pembaca) pada tanggal 28 Desember 2020, berupa video yang menyajikan beragam destinasi wisata di Kota Semarang seperti Kawasan Kota Lama, Gedung Lawang Sewu, Tugu Muda, Masjid Agung Jawa Tengah, Goa Kreo, Pantai Marina, dan lain-lain dengan gambar video yang cukup artistik dengan durasi 2 menit lebih 53 detik. Captions yang disajikan merupakan jenis penulisan persuasif dengan menggabungkan teknik asosiasi dan teknik tataan. Teknik Asosiasi yaitu penyajian pesan komunikasi dengan cara menumpahkannya pada suatu obyek atau peristiwa yang sedang menarik perhatian khalayak. Sementara teknik tataan adalah upaya menyusun pesan komunikasi sedemikian rupa, sehingga enak didengar atau dibaca dan menimbulkan motivasi untuk melakukan sebagaimana disarankan oleh pesan tersebut. Dari hal tersebut terlihat bahwa apabila gambar/video yang tersaji menarik dan penulisan captions persuasi juga menarik maka akan meningkatkan respon khalayak pembaca dengan meningkatnya likes dan views di unggahannya. 
Berdasarkan data temuan terkait isi unggahan pada akun instagram @disbudparkotasemarang dapat dijelaskan bahwa akun ini dikelola dengan perencanaan dan teknik framing yang sudah direncanakan sebelumnya. Hal ini sejalan dengan data dari informan dari kabid IKP Kominfo Kota Semarang yang sebelumnya juga bertugas di Dinas Kebudayaan dan Pariwisata. Informan menyampaikan bahwa terdapat koordinasi terkait jenis unggahan yang dimuat di media pemerintah kota dengan masing masing kedinasan yang terkait sehingga informasinya saling terintegrasi.

Informan membenarkan bahwa Kota Semarang memang masih melangkah menuju kota tujuan wisata dan sedang gencar-gencarnya menggalakkan konten terkait destinasi dan hal-hal pendukung wisata. Hal ini sebagaimana hasil wawancara dengan informan yaitu

"...memang sedang digalakkan konten yang terkait destinasi wisata..."

"Untuk kawasan Kota lama Semarang, memang menjadi orientasi destinasi wisata yang sedang dipopulerkan, agar masyarakat memiliki alternative destinasi wisata yang lain selain hanya Tugumuda dan Lawang sewu, maupun kampung pelangi yang sudah lebih dulu populer bila menyebut Semarang..."

Dalam ranah komunikasi terkait branding menyebutkan bahwa penyampaian pesan yang massif, terencana, terukur dan secara terus menerus melalui media massa akan menancapkan image suatu brand ke benak khalayak secara lebih cepat. Maka tidaklah mengherankan bila kemudian ikon terkait bangunan cagar budaya yang ada di kota lama seperti Gereja Blenduk menjadi cukup popular juga bila dikaitkan/ diasosiasikan dengan Kota Semarang, dilihat dari intensitas unggahannya pada akun instagram @disbudparkotasemarang. Gereja Blenduk ini memang yang paling sering diunggah bila berkaitan dengan kota lama Semarang.

"kedepannya memang sudah ada rencana menampilkan gedung gedung yang lain di kawasan kota lama. Dan nantinya tidak melulu hanya Gereja Blenduk...hanya saja prosesnya setahap demi setahap terkait destinasi wisata baru semarang agar muncul rasa penasarannya..."

Lebih lanjut data dari informan menjelaskan bahwa pemunculan ikon-ikon identitas kota yang sudah stabil terkait Kota Semarang seperti Tugu Muda, bangunan Lawang Sewu, Gereja Blenduk tetap akan digunakan untuk menarik lebih dalam khalayak agar mereka mengingat Kota Semarang sembari kedepannya dimunculkan ikon-ikon yang lain. Teknik penulisan teks/pesan pada captions feed Instagram berdasarkan analisa menggunakan penerapan konsep agenda setting media dan framing pesan. Konsep agenda setting adalah konsep yang menyampaikan bahwa pihak pengelola media memiliki kemampuan memuat dan menyusun isu-isu yang dianggap penting untuk ditampilkan kepada khalayak. Harapan yang diinginkan dengan adanya penyusunan agenda ini makan akan menjadi perbicangan di kalangan masyarakat (pembaca) dan akhirnya tujuan besarnya merubah atau mempengaruhi agenda kebijakan (MCCombs \& Shaw, 2019).

Framing pesan dimedia sangat berkaitan dengan komunikasi persuasif. Kenneth E Kim mengemukakan bahwa framing as a Strategic Persuasive Message Tactic. Lebih lanjut Kim menjelaskan bahwa pesan komunikasi secara umum mengacu cara dimana pilihan masalah yang diangkat terkait dengan strategi pengungkapan pesan dan efek framing 
yang ditimbulkan tergantung pada bagaimana representasi dari pilihan masalah yang diangkat, pembingkaian pesannya, pengaruh respon kognitif atau behavioral khalayaknya (Y.-J. Kim, 2006; Jones, Sinclair \& Courneya, 2003; Meyerowitz \& Chaiken, 1987 in Kim, 2015). Terdapat pendekatan framing penulisan pesan dengan menonjolkan sisi positif (Gain Framing) untuk menumbuhkan minat, ketertarikan dan juga terdapat pendekatan framing penulisan pesan dengan lebih menojolkan sisi negatif atau kejelekan untuk membuat pembaca/khalayaknya waspada bahkan disengaja untuk menimbulkan kecemasan. Istilah untuk pendekatan framing pesan dari sisi negatif oleh Kim disebut dengan Loss Framing. Dalam konteks komunikasi yang berhubungan dengan pariwisata teknik Gain Framing lebih sesuai karena terkait dengan pleasure.

Effendy dalam (Erviani, 2017: 239) menjabarkan teknik-teknik dalam komunikasi persuasif yaitu: (1) Teknik Asosiasi adalah penyajian pesan komunikasi dengan cara menumpahkannya pada suatu obyek atau peristiwa yang sedang menarik perhatian khalayak. (2) Teknik Integrasi ialah kemampuan komunikator untuk menyatukan diri secara komunikatif dengan komunikan. Ini berarti bahwa melalui kata-kata verbal maupun non verbal komunikator menggambarkan bahwa ia "senasib" dan dengan karena itu menjadi satu dengan komunikan. (3) Teknik Ganjaran adalah kegiatan untuk mempengaruhi orang lain dengan cara mengiming-iming hal yang menguntungkan atau menjanjikan harapan. (4) Teknik Tataan adalah upaya menyusun pesan komunikasi sedemikian rupa, sehingga enak didengar atau dibaca dan menimbulkan motivasi untuk melakukan sebagaimana disarankan oleh pesan tersebut. (5) Teknik Red-herring adalah seni seorang komunikator untuk meraih kemenangan dalam perdebatan dengan mengelakkan argumentasi yang lemah untuk kemudian mengalihkannya sedikit demi sedikit ke aspek yang dikuasainya guna dijadikan senjata ampuh dalam menyerang lawan.

Berdasarkan data terkait teknik penulisan pesan captions di akun instagram @disbudpakotasemarang memberikan penjelasan bahwa teknik tataan adalah teknik yang menduduki porsi yang paling besar yaitu sebesar 33,33\% dari seluruh postingan yang berhubungan dengan kota lama dan teknik asosiasi paling jarang digunakan selama masa obyek pengamatan yaitu sebesar $8,34 \%$ atau sebanyak $5 \%$. Teknik persuasi jenis Tataan dapat di contohkan pada tebel 7 dibawah ini:

Tabel 9. Contoh screen shoot postingand captions dengan teknik persuasi tataan pada akun instagram @disbudparkotasemarang [Sumber: akun instagram@disbudparkotasemarang 24 Juni 2019]

\begin{tabular}{|c|l|}
\hline Gambar & \multicolumn{1}{|c|}{ Captions } \\
\hline & $\begin{array}{l}\text { Kota cantik yang meninggalkan banyak sejarah } \\
\text { dan kenangan. Kota tua Semarang, yang dari } \\
\text { dulu sampai sekarang tetap cantik dan } \\
\text { mempesona. }\end{array}$ \\
Sudah main kesini?
\end{tabular}


Teknik persuasi dengan cara asosiasi adalah penyajian pesan komunikasi dengan cara menumpahkannya pada suatu obyek atau peristiwa yang sedang menarik perhatian khalayak. Contoh jenis captions ini diunggah saat pemerintah Kota Semarang tengah gencar mensosialisasikan kegiatan Car Free Night di Kota lama Semarang, namun di saat yang sama terdapat keluhan akan minimnya moda transportasi dan lahan parkir di kawasan ini.

Tabel 10. Contoh screen shoot postingan dan captions dengan teknik persuasi asosiasi pada akun @disbudparkotasemarang

[Sumber: @disbudparkotasemarang 10 Oktober 2019]

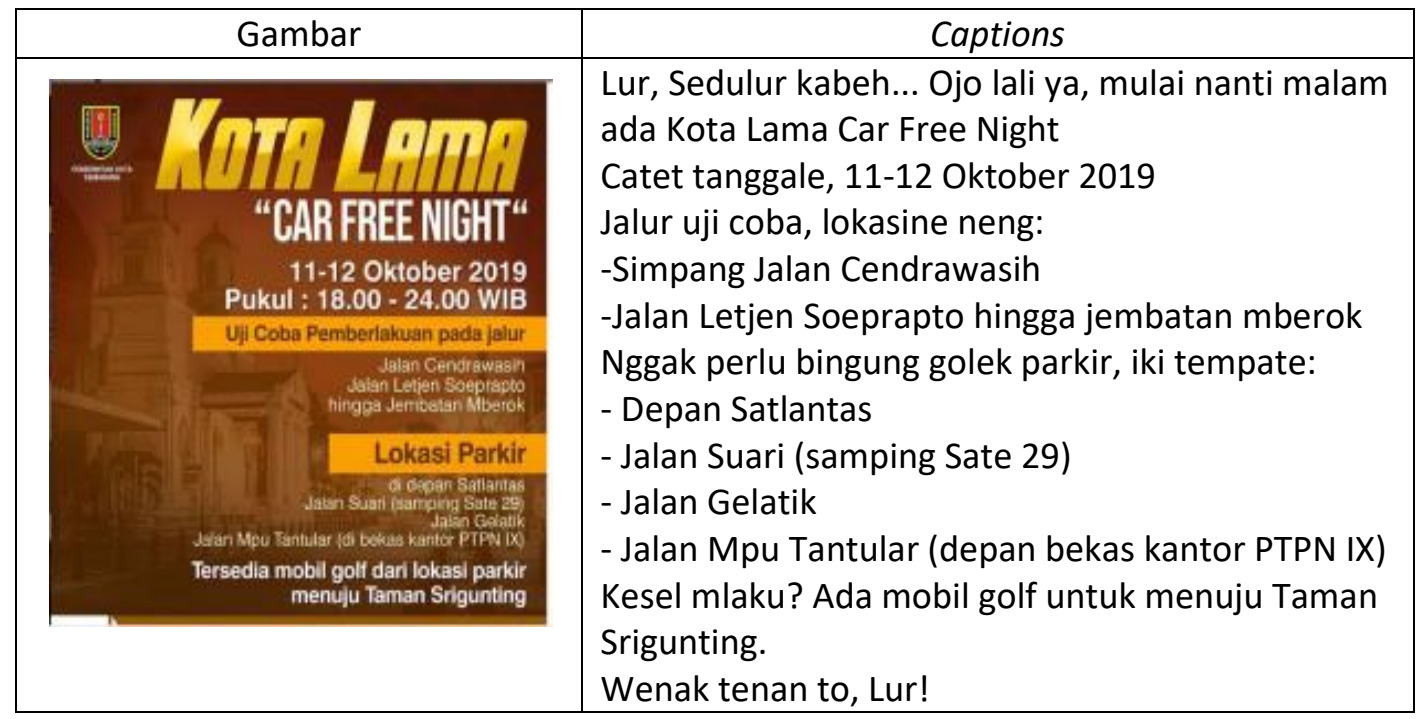

Sementara teknik Red-Herring sama sekali tidak muncul. Teknik komunikasi persuasif model ini cocok digunakan apabila berkomunikasi tatap muka secara langsung dan bersifat timbal balik( dua arah). Model ini tidak cocok di sampaikan untuk model konten di media sosial khususnya instagram yang terbatas ruangnya dan bersifat satu arah.

\section{KESIMPULAN}

Isi unggahan akan identitas bangunan cagar budaya yang terkait kawasan kota lama Semarang di akun insagram @disbudparkotasemarang adalah Gereja Blenduk. Dengan intensitas sebanyak 23 kali unggahan. Tahun 2019 merupakan tahun yang paling tinggi dalam menampilkan kawasan kota lama semarang di feed instagram, yaitu sebesar 54 postingan dibandingkan dengan unggahan tahun lainnya.

Unggahan yang paling banyak mendapatkan respon dengan banyak dilihat orang adalah video dengan views 1764 yang diunggah pada tanggal 28 Desember 2019 yang berisi tentang Destinasi beberapa Wisata Kota Semarang Paling Hit. Sementara untuk unggahan berbentuk foto, unggahan foto saat presiden Jokowi berkeliling Kota lama yang diunggah pada tanggal 30 Desember 2019 adalah yang paling banyak yang di likes, sejumlah 947 kali. Terdapat keterkaitan bahwa apabila gambar/video yang tersaji menarik dan penulisan captions persuasi juga menarik maka akan meningkatkan respon khalayak pembaca dengan jumlah views atau like yang banyak pula. 
Teknik penulisan captions dan unggahan baik gambar, video maupun foto telah melalui perencanaan di bagian yang terkait dengan berpegang pada konsep agenda setting media guna menjadikan unggahan pesan yang berhubungan tujuan yang ingin diraih yaitu menjadikan Kota Semarang sebagai kota tujuan wisata. Empat jenis teknik komunikasi persuasif digunakan saat menulis captions pada feed instagram @disbudparkotasemarang. Satu teknik penulisan persuasive yaitu Red Herring belum muncul, hal ini bisa dimengerti karena teknik redherring lebih cocok digunakan apabila melakukan komunikasi persuasi dengan melakukan dialog atau tatapmuka.

Untuk penelitian selanjutnya bisa lebih dikembangkan dengan memfokuskan pengamatan terkait update informasi pada Instastories. Kelemahan penelitian ini tidak mengamati posting story/instastories instagram@disbudparkotasemarang karena keterbatasan waktu. Unggahan di instastories hanya bertahan dalam waktu 24 jam meski postingan di bagian ini lebih terkini.

\section{DAFTAR PUSTAKA}

Adiwibawa, B. P., \& Prabowo, D. (2016). Karakter Fasad Bangunan Ikonik Kota Sebagai Alternatif Desain Identitas Kota Semarang. ANDHARUPA: Jurnal Desain Komunikasi Visual \& Multimedia, Vol.02 No.(January 2016), 23-32.

Ernawati, J. (2014). Hubungan Aspek Residensial Dengan Place Identity Dalam Skala Urban. Jurnal of Environment Engineering \&sustainable Technology, 01(01), 21-32.

Erviani, O. (2017). Teknik Komunikasi Persuasif Dinas Kota Samarinda. Ilmu Komunikasi, 5961(3), 235-247.

Hendi Sukses Realisasikan Janji Kembangkan Kota Lama/radarsemarang.jawapos.com. (2019). https://radarsemarang.jawapos.com/berita/semarang/2019/08/27/ hendi-sukses-realisasikan-janji-kembangkan-kota-lama/

Instagram@disbudparkotasemarang

Inn, K. (2004). Plan For City Identity Establishment And City Introduction: Study Objective. 233-240.

Jateng, R. M. (2019). Semarang Sering Disebut Kota Transit, Ini Kata Hendi. https://metrojateng.com/semarang-sering-disebut-kota-transit-ini-katahendi/

Kim, K. E. (2015). Framing as a Strategic Persuasive Message Tactic. In The Routledge Handbook of Strategic Communication (pp. 285-299). Routledge.

Lynch, Kevin. (1960). The Image of the City. MIT Press Cambridge

McCombs, M., \& Shaw, D. (2019). Agenda Setting Theory. In A First Look At Communication Theory, Tenth Edition (Tenth Edit, P. 368). McGraw-Hill Education.

Profil Kota. http://semarangkota.go.id/p/33/profil_kota. (2018). Pemerintah Kota Semarang. http://semarangkota.go.id/p/33/profil_kota

Pujakesuma, A. (2019). Hendi Sukses Lepas Cap Semarang Sebagai Kota Transit. https://semarang.merdeka.com/kabar-semarang/hendi-sukses-lepas-capsemarang-sebagai-kota-transit-190610q.html 
Putri, F. I., LUkmantoro, T., Dwiningtyas, H., \& Gono, J. N. (2015). Teknik-teknik Persuasif Dalam Media Sosial ( Studi Analisis Isi Kualitatif Pada Akun Mentor Parenting. Interaksi.

Ratiu, D. E. (2013). Creative cities and/or sustainable cities: Discourses and practices. City, Culture and Society, 4(3), 125-135.

Suprayoga, G. B. (2008). Identitas Kota Sawahlunto Paska Kejayaan Pertambangan Batubara. Journal of Regional and City Planning, 19(2), 1-21.

Yanuarsari, D. H., \& Haryadi, T. (2019). Mock Up Digital Storytelling Untuk Historikal Monumen Tugumuda Semarang Sebagai Media Edukasi. Comnews, 296-309. https://proceeding.umn.ac.id/index.php/COMNEWS/article/view/1103 